Asia Proceedings of Social Sciences

(APSS)

www.readersinsight.net/APSS

\title{
A Intervening Role of Co-creation Strategy on Relationship between on Business Model Innovation and Customer Experience
}

\section{Leonardus Wahyu Wasono*}

Doctor of Research in Management, Bina Nusantara University Indonesia

\section{Sasmoko}

Faculty of Humaniora, Bina Nusantara University Indonesia

\section{Firdaus Alamsjah}

Business School, Bina Nusantara University Indonesia

\section{Elidjen}

Business School, Bina Nusantara University Indonesia

*Corrosponding author's Email: mihardjo@gmail.com

Peer-review under responsibility of $4^{\text {th }}$ Asia International Conference 2018 editorial board (http://www.utm.my/asia/our-team/) (C) 2018 Published by Readers Insight Publisher, lat 306 Savoy Residencia, Block 3 F11/1,44000 Islamabad. Pakistan, info@ readersinsight.net 


\section{Research High Iight s}

The Study proposed three hypothesis to assess the direct impact on relation between customer and business model innovation and between customer experience and co-creation strategy, and to assess the indirect impact through intervening role of co-creation strategy on relationship between business model innovation and customer experience. The study has unit analysis of Indonesia telecommunication incumbent firms. The result shows that co-creation strategy plays significant role on relationship between business model innovation and customer experience, while customer experience could not have direct significant impact on developing business model innovation. This finding has implication for incumbent firm in managing digital transformation has to develop collaboration with stakeholder including customer based on the development customer experience to strengthen business model innovation. The result the study based on the hypothesis development can be shown in figure 1.

\section{G r a p h i c a I A b s t r a c t (optional)}

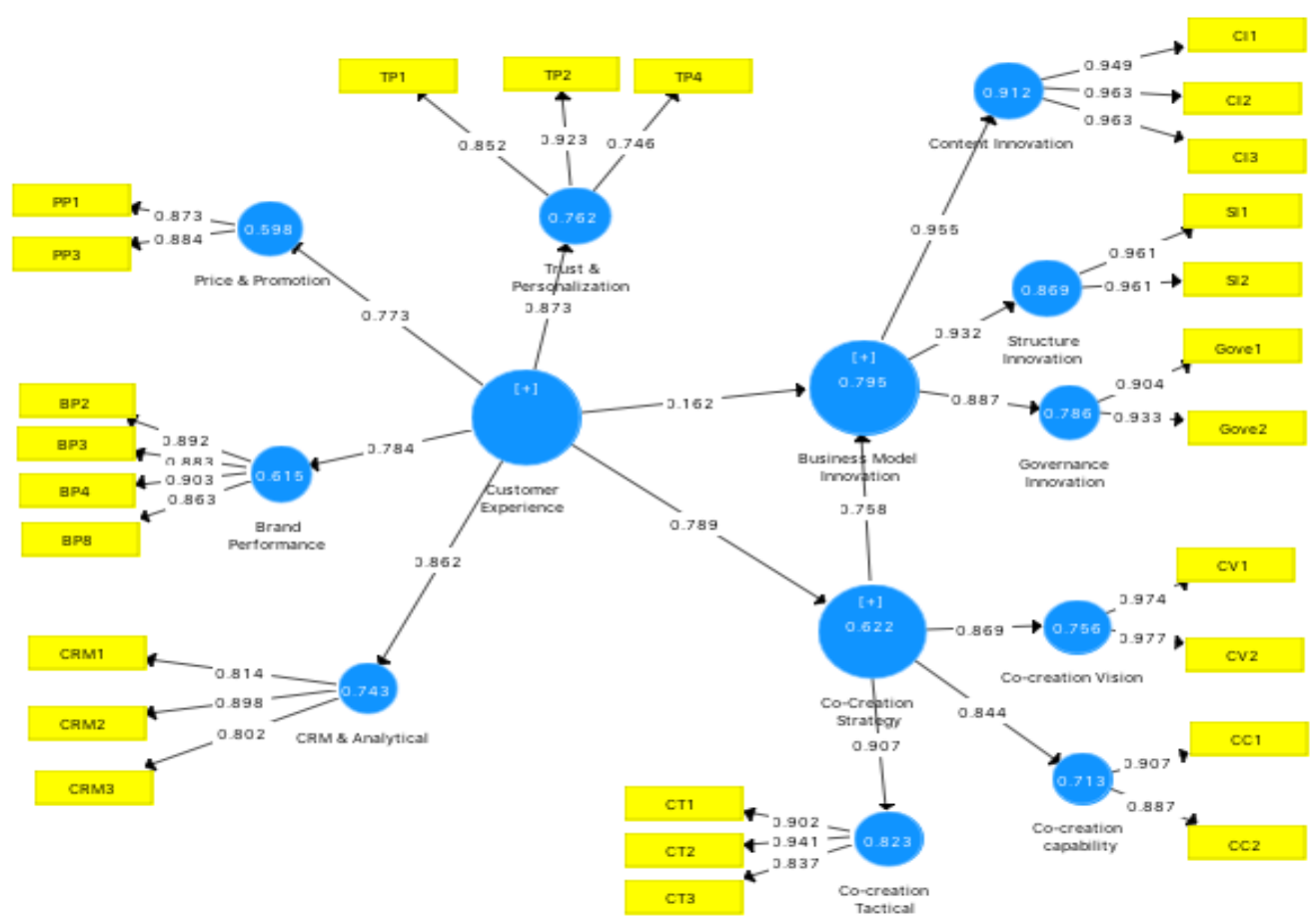

Figure 1. The Research Model Result 


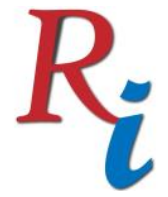

Asia Proceedings of Social Sciences

(APSS)

www.readersinsight.net/APSS

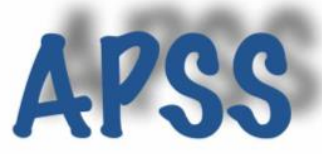

\section{Research Objectives}

In disruptive and digital era through internet, mobile big data, blockchain, incumbent firm has face issues on transformation to anticipate the change of market, customer and business model. the all parties are connected through digital technology. New business model innovation is the key element in digital transformatin (Berman, 2012), while in developing of business model in fastest way is required co-cration with stakeholder. The development of business model innovation and co-creation has to developed based on customer (Christensen, 1997) while in digital is based on customer experience since customer can connected to the firms through virtual and online. The study on business model with marketing such as customer expererience and co-creation strategy was limited (Coombes \& Nicholson, 2013) and since digital technology in indonesia telecommunication is in early stage (Das, Gryseels, Sudhir, \& Tan, 2016) hence the study aims to assess moderating role of co-creation strategy on relationship between business model innovation and customer experience. The analysis path of effectiveness in developing co-creation strategy and business model is important for Indonesian telecommunication firms in facing changing in digital technology. The study is expected contributed to management practice in managing digital transformation to find the proper path analysis in digital transformation.

\section{Methodology}

This study is emperical study based on unit analyis of Indonesia Telecommunication firms with the management of these firms as the observed unit. We identified the total population based on criterira of incumbent firms, is made up of 445 companies including 312 Internet Service Provider (ISP) firms and network providers and its partners (34 satellite firms, 27 towers, and 72 Telkom subsidiaries and affiliates). Based on the research model, there are 1 endogenous construct with 2 (two) arrow directed and based on Cohen (Cohen, 1992) the minimum sample size is 33 respondents for this model with 5\% Probability error, $80 \%$ statistical power and minimum $\mathrm{R} 2=0.25$. This study used 35 sample of telecommunication firms which is higher than recommendation in which $95 \%$ of them are senior leaders at General Manager levels or higher. Data was collected via online through website questionnaire and distributed through social media application such as Messenger, WhatsApp's, and Telegram or by email. Since the limitation of data sample, statistical a tool of analysis is Smart PLS (Partial Least Square). 


\section{Results}

To asses the validity and reliability, the study conducts two assesment testing : (1) Mesurement model to assess the relationship between latent variable and their indicators, through convergent validity, composite relibility, discriminant validity, (2) structural model and hypothesis testing to measure endegous variable and direct and indirect effect to come up with hypothesis testing (Henseler, Hubona, \& Ray, 2016). The result of measurement testing shows that all latent variable and their indicators are valid. The structural model show that the structural model has adequate predictive relevance. Hypothesis testing show as follow: on direct effect test, customer experience has significant impact to co-creation strategy with result of path coefficient score is 0.789 , t-Statisticsi s 8.706 and p-Value is 0.000 . while the relationship between customer experience and business innovation show that customer experience does not have significant impact to business model innovation, with the result of path coefficient score is 0.159 , t-Statistics is 0.826 and $\mathrm{p}$-Value is 0.409 , however the relationship between co-creation and business innovation, it proves that co-creation has significant impact on co-creation strategy.

According to the indirect effect test, it proves that co-creation has significant impact as mediating role on relationship between business model innovation and customer experience.

\section{Findings}

The development of co-creation strategy could use customer experience to attract customers and stakeholders capability from outside to be integrated into value chain. The finding shows that co-creation strategy is formed from the co-reation tactical dimension, it means that the implementable of co-creation is most significant impact rather than conceptual. The Business model innovation is formed from content and structure innovation, it shows that the performance result is more important rather than governance. While the customer experience is form from personalization and CRM analytical dimension, it means personalisation is important supported by analytical tool such as big data in digital era. 
www.readersinsight.net/APSS

\section{References}

Berman, S. J. (2012). Digital transformation: Opportunities to create new business models. Strategy and Leadership, 40(2), 16-24. https://doi.org/10.1108/10878571211209314

Christensen, C. M. (1997). Innovator 's Dilemma. Harvard Business School Press.

Cohen, J. (1992). Quantitative Methods in psychology: A Power Primer. Psychological Bulletin, 112(1), 155-159. https://doi.org/10.1016/j.jorganchem.2011.01.025

Coombes, P. H., \& Nicholson, J. D. (2013). Business models and their relationship with marketing: A systematic literature review. Industrial Marketing Management, 42(5), 656-664. https://doi.org/10.1016/j.indmarman.2013.05.005

Das, K., Gryseels, M., Sudhir, P., \& Tan, K. T. (2016). Unlocking Indonesia's Digital Opportunity. McKinsey \& Company, (October), 1-28.

Henseler, J., Hubona, G., \& Ray, P. A. (2016). Using PLS path modeling in new technology research: Updated guidelines. Industrial Management and Data Systems, 116(1), 2-20. https://doi.org/10.1108/IMDS-09-2015-0382 